\title{
Author Correction: Maintenance, reserve and compensation: the cognitive neuroscience of healthy ageing
}

Roberto Cabeza, Marilyn Albert, Sylvie Belleville, Fergus I. M. Craik, Audrey Duarte, Cheryl L. Grady, Ulman Lindenberger, Lars Nyberg, Denise C. Park,

Patricia A. Reuter-Lorenz, Michael D. Rugg, Jason Steffener and M. Natasha Rajah

Nature Reviews Neuroscience (2018) https://doi.org/10.1038/s41583-018-0068-2

Published online 10 October 2018

In the originally published version of article, there were two errors in the references.

The reference "Nilsson, J. \& Lövdén, M. Naming is not explaining: future directions for the "cognitive reserve" and "brain maintenance" theories. Alzheimer's Res. Ther. 10, 34 (2018)" was missing. This reference has been added as REF. ${ }^{14}$ in the HTML and PDF versions of the article and cited at the end of the sentence "However, over the years, these terms have been used inconsistently, creating confusion and slowing progress." on page 701 and at the end of the sentence "If reserve is defined merely as the factor that individuals with greater reserve have and then this factor is used to explain why some individuals have greater reserve, the argument is clearly circular." on page 704. The reference list has been renumbered accordingly.

In addition, in the original reference list, REF. ${ }^{91}$ was incorrect. The reference should have read "Cabeza, R. Hemispheric asymmetry reduction in older adults. The HAROLD model. Psychol. Aging 17, 85-100 (2002)". This reference, which is REF. ${ }^{92}$ in the corrected reference list, has been corrected in the HTML and PDF versions of the article.

https://doi.org/10.1038/s41583-018-0086-0 I Published online 7 November 2018

\section{Publisher Correction: Maintenance, reserve and compensation: the cognitive neuroscience of healthy ageing}

Roberto Cabeza, Marilyn Albert, Sylvie Belleville, Fergus I. M. Craik, Audrey Duarte, Cheryl L. Grady, UIman Lindenberger, Lars Nyberg, Denise C. Park, Patricia A. Reuter-Lorenz, Michael D. Rugg, Jason Steffener and M. Natasha Rajah

Nature Reviews Neuroscience (2018) https://doi.org/10.1038/s41583-018-0068-2

Published online 10 October 2018

In Figure $3 \mathrm{~b}$ of the originally published article, the colours of the bars were incorrectly reversed. The bars shown in green should have been shown in blue to represent the findings from older adults, whereas the bars shown in blue should have been shown in green to represent the findings from young adults. This has been corrected in the HTML and PDF versions of the article.

https://doi.org/10.1038/s41583-018-0087-z I Published online 7 November 2018

b

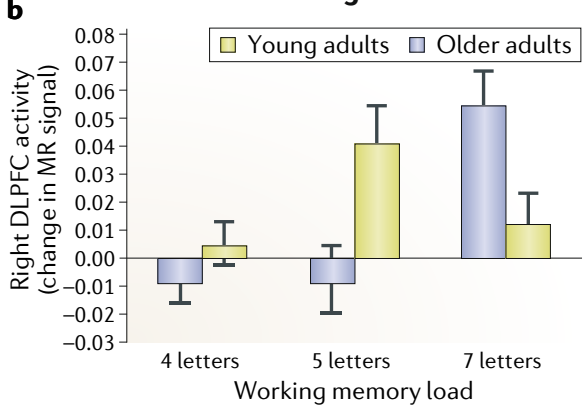

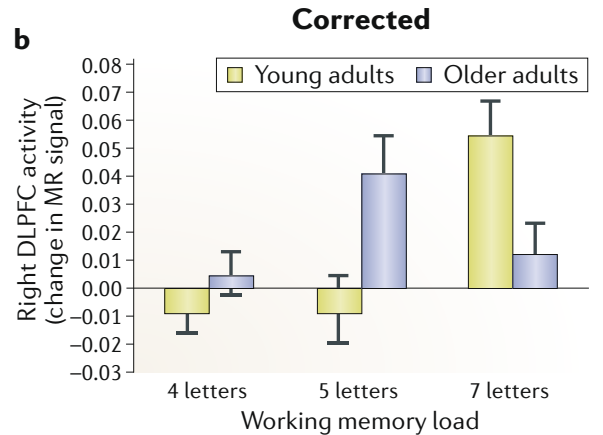

Fig. 3 | Original and Corrected. 